\title{
Phage-typing patterns and lysogenicity of methicillin-resistant strains of Staphylococcus aureus from Sydney, Australia, 1965-85
}

\author{
ALISON M. VICKERY, MARY A. BEARD-PEGLER* and ELIZABETH STUBBS* \\ Department of Microbiology, Fairfax Institute of Pathology, Royal Prince Alfred Hospital, Sydney, NSW \\ 2050, and 'Department of Infectious Diseases, The University of Sydney, Sydney NSW 2006, Australia
}

\begin{abstract}
Summary. Methicillin-resistant strains of Staphylococcus aureus isolated at the Royal Prince Alfred Hospital since 1965 were differentiated by phage-typing and by their lysogenic status. Most of these strains were isolated during two periods, 1965-72 and 1976 85. Nearly all of the strains isolated in the first period had one of four phagetyping patterns. Strains with each typing pattern carried two prophages; these eight phages were all different, as characterised by serological grouping and lytic spectrum. Lysogenisation of the non-lysogenic strain 1489 with each of these phages narrowed its phage-typing pattern; the typing pattern of the double lysogens was generally similar to and occasionally identical with that of the host strain that had yielded the pair of phages. In the second period, strains with one of five other phage-typing patterns predominated. Representatives of each of these carried the lysogenic phage $C$. The first methicillin-resistant strain carrying this phage had been isolated in 1974. The current methicillin-resistant $S$. aureus strains thus appear to form a distinct group that can be differentiated from those seen in earlier years.
\end{abstract}

\section{Introduction}

Methicillin-resistant strains of Staphylococcus aureus (MRSA) have been isolated at the Royal Prince Alfred Hospital (RPAH), Sydney, since 1965 (Rountree and Beard, 1968), 4 years after the introduction of the drug. By $1970,18.5 \%$ of all $S$. aureus strains isolated at the RPAH were resistant to methicillin (Rountree and Vickery, 1973). Nearly all of these strains showed one of four patterns of lysis by members of the Basic International Set of Typing Phages at routine test dilution (RTD). After 1972 the number of isolates of MRSA decreased markedly, and by 1975 these formed only $0.5 \%$ of the total for $S$. aureus. From 1976 onwards the isolation rate again increased (Vickery et al., 1983) and subsequently remained high.

Since 1980 there have been many reports of MRSA causing infections in hospitals in Australia (McDonald et al., 1981; King et al., 1982; Pavillard et al., 1982), Ireland (Cafferkey et al., 1983), England (Bradley et al., 1985) and the USA (Schaefler et al., 1981). These more recent isolates of MRSA were not typable with the Basic International Set of Typing Phages at RTD. However, strain differentiation among MRSA prevalent in Austra-

Received 20 Aug. 1985; revised version accepted 17 Jan. 1986. lia at this time was possible if these phages were applied at 100 times the strength of the RTD (100 RTD), together with a set of additional phages (Vickery et al., 1983).

We also found that all 23 representatives of MRSA strains prevalent in our hospital from January 1980 to December 1984 carried the lysogenic phage C (Beard-Pegler and Vickery, 1985), but the presence of this phage had little effect on phagetyping patterns. The present report reviews the phage-typing patterns of MRSA isolated at the RPAH between 1965 and 1985 and reports on the lysogenicity of representative strains prevalent in the hospital at various times.

\section{Materials and methods}

\section{Methicillin-resistant strains of S. aureus}

Since 1965 a total of 2475 isolations of methicillinresistant slide-coagulase-positive staphylococci have been made at the RPAH. These strains were phage-typed soon after isolation, and they were stored on nutrientagar slopes at room temperature.

Selected strains were later used in studies of lysogenicity. No. 1489 is an apparently non-lysogenic MRSA with a very wide phage-typing pattern (Vickery et al., 1983). In preliminary experiments, several strains representative of 
each of the four phage-typing patterns that together formed the majority among MRSA isolated during 196572 were tested for the presence of lysogenic phages. Strains with the same typing patterns gave identical results, and nos. 5058, 5045, 5531 and 6803 were selected as prototypes, each representing one of the patterns. Twenty-seven other strains, including representatives of each of the typing patterns encountered between 1973 and 1979, were also studied, together with three representatives of a new typing pattern encountered in 1984-85.

\section{Other S. aureus strains}

Propagating strains (Ps) and test strains (Ts) of the Basic International Set of Typing Phages were used to determine the host ranges of phages.

\section{Media and antibiotic-sensitivity-testing methods}

These have been described previously (Vickery et al.. 1983).

\section{Phages}

Phage-typing was performed by the method of Blair and Williams (1961). MRSA strains isolated before 1973 were typed with the Basic International Set of Typing Phages, which then included phage 42D. Phage 88 was first used in 1969. MRSA isolated after 1973 were typed with the current Basic Set which included phage 95 but not phage 42D. Phage 90 was first used in 1980. MRSA strains isolated after 1980 were also typed with five additional phages isolated in 1982 (Vickery et al., 1983). Lysogenic phages were obtained by (a) induction of MRSA with ultraviolet light (Gorrill and Gray, 1956), or (b) by treatment of early exponential-phase broth cultures with mitomycin $\mathrm{C}, 1.0 \mathrm{mg} / \mathrm{L}$. All phage filtrates were propagated on strain 1489. All new phages were characterised by their plaque morphology, host range and serological type (Rippon, 1956). Lysogenic phages were numbered according to the last two digits of the number of the strain of staphylococcus from which they were derived, together with a letter indicating the distinguishing feature of their plaque morphology, e.g., $\mathrm{L}=$ large plaque, $\mathrm{C}=$ clear plaque. $\mathrm{T}=$ tiny plaque, $\mathrm{M}=$ plaque of medium size.

\section{Lysogenisation}

The method of lysogenisation and identification of lysogens has been described (Vickery et al., 1983). In lysogenised staphylococci, the phage numbers are given in parentheses after the numbers of the staphylococcal strains: in double lysogens, the order of the phage numbers corresponds to the order of lysogenisation.

\section{Results}

Since 1965 there have been two distinct periods during which MRSA were isolated in large numbers in the RPAH (table I). In the first (1967-72) there were 739 isolates, with the highest frequencies in 1969 and 1970 (respectively 220 and 202/year). MRSA were seldom seen in 1973, 1974 and 1975 ( $<10$ isolates/year). In 1976, however, they reappeared in considerable numbers, and from 1978 to 1985 the annual rate of isolation was never lower than 150 and was often considerably in excess of this.

\section{Phage-typing patterns of MRSA strains}

When typed by the Basic Set of phages at RTD, strains isolated between 1967 and 1975 nearly all gave one of four reactions: (1) a broad pattern of lysis by lytic-group III phages $(6 / 47 / 53 / 54 / 77 / 83 \mathrm{~A} /$ 84/85/88); (2) 77/84/85/88; (3) 88; and (4) untypable (Rountree and Vickery, 1973); the untypable strains were not lysed by the phages at 100 RTD. Very few of the strains isolated after 1976 were typable with the basic-set phages at RTD, but most of them gave reactions at $100 \mathrm{RTD}$; these reactions included four patterns: (1) $84 / 85$; (2) $83 \mathrm{~A} / 85 / 95 / 90 / 88$; (3) $77 /$ 83A/84/85/95/90/88; and (4) untypable (Vickery et al., 1983). However, when examined under rigidly standardised test conditions, many of these untypable strains (designated NT* in table I) consistently gave one or two plaques with phages $83 \mathrm{~A}, 85,95$ and 88 . These untypable strains are lysogenised by phage $\mathrm{C}$ only, in contrast to the untypable group isolated before 1975 which was lysogenised by two different phages (tables II \& III). More recently, MRSA with two other distinctive phage-typing patterns at 100 RTD have been seen: $77 / 85 / 88$ from 1983 onwards and 29/85/88 in 1984 and 1985.

MRSA with typing patterns other than those specified above (designated as Miscellaneous in table I) were encountered infrequently.

\section{Lysogenicity of strains isolated in 1965-72}

Two distinct lysogenic phages were isolated from each of the strains 5058, 5045, 5531 and 6803 (table II). Full characterisation of these phages confirmed that all eight were distinct (table III). The two phages from each strain belonged to different serological groups, and each phage had a distinct lytic spectrum, characterised by the lysis of two or more different Ps or Ts. Furthermore, none of these phages was identical with any of the four phages - C, 47T, 67R and $87 \mathrm{M}$ - that were obtained from MRSA strains isolated at the RPAH after 1980 (Beard-Pegler and Vickery, 1985), the serological 


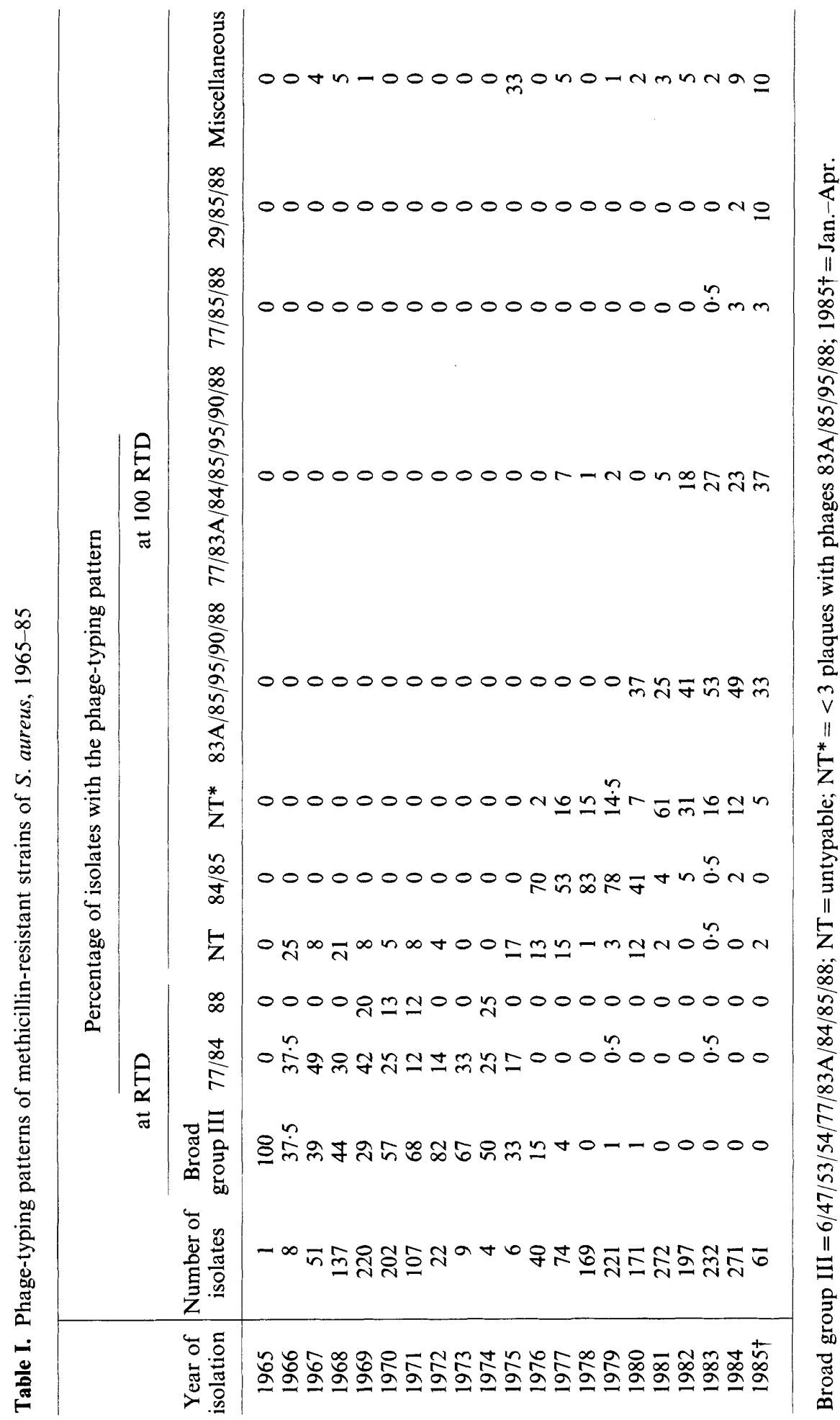


Table II. Lysogenicity of MRSA strains, 196572

\begin{tabular}{l|ll}
$\begin{array}{l}\text { Strain } \\
\text { no. }\end{array}$ & Typing patterns at RTD & $\begin{array}{l}\text { Lysogenic } \\
\text { phages } \\
\text { isolated }\end{array}$ \\
\hline 5058 & $6 / 47 / 53 / 54 / 77 / 83 \mathrm{~A} / 84 / 85 / 88$ & $58 \mathrm{~L}$ \\
& & $58 \mathrm{C}$ \\
5045 & $77 / 84 / 85 / 88$ & $45 \mathrm{~L}$ \\
5531 & 88 & $45 \mathrm{C}$ \\
& & $31 \mathrm{~T}$ \\
6803 & Untypable & $31 \mathrm{~L}$ \\
& & $03 \mathrm{~L}$ \\
& & $03 \mathrm{M}$
\end{tabular}

groups and lytic spectra of which are also shown in table III.

Lysogenisation of strain 1489. The non-lysogenic strain 1489 was lysogenised with each of the eight phages obtained from the representative 1965-72 strains, both singly and as pairs corresponding to the original associations of the phages. Lysogenisation with single phages resulted in various degrees of narrowing of the typing pattern of strain 1489 (table IV). For example, of the phages from strain 5058, phage 58L (serological group A) gave immunity to phage 42D (group F) and reduced sensitivity to phages $79,83 \mathrm{~A}$ and 85 (group B); and phage $58 \mathrm{C}$ (group F) reduced sensitivity to phages $83 \mathrm{~A}$ and 85 (group B). Lysogenisation with other phages, e.g.,

Table III. Characterisation of lysogenic phages from MRSA strains, 1965-85

\begin{tabular}{|c|c|c|c|c|c|c|c|c|c|c|c|c|c|c|}
\hline \multirow[b]{2}{*}{$\begin{array}{l}\text { Phage group } \\
\text { of strain }\end{array}$} & \multirow[b]{2}{*}{$\begin{array}{l}\text { Strain } \\
\text { no. }\end{array}$} & \multicolumn{12}{|c|}{ Titre on propagating and test strains of phage } & \multirow[b]{2}{*}{$\begin{array}{c}13 \mathrm{M} \\
\text { (B) }\end{array}$} \\
\hline & & $\begin{array}{l}58 \mathrm{~L} \\
(\mathrm{~A})^{*}\end{array}$ & $\begin{array}{l}58 \mathrm{C} \\
(\mathrm{F})\end{array}$ & $\begin{array}{l}45 \mathrm{~L} \\
(\mathrm{~A})\end{array}$ & $\begin{array}{l}45 \mathrm{C} \\
(\mathrm{F})\end{array}$ & $\begin{array}{l}31 \mathrm{~T} \\
\text { (A) }\end{array}$ & $\begin{array}{l}31 \mathrm{~L} \\
(\mathrm{~F})\end{array}$ & $\begin{array}{l}03 \mathrm{~L} \\
(\mathrm{~B})\end{array}$ & $\begin{array}{c}03 \mathrm{M} \\
(\mathrm{F})\end{array}$ & $\begin{array}{l}\mathrm{C} \\
(\mathrm{F})\end{array}$ & $\begin{array}{l}67 \mathrm{R} \\
\text { (A) }\end{array}$ & $\begin{array}{c}87 \mathrm{M} \\
(\mathrm{F})\end{array}$ & $\begin{array}{l}47 \mathrm{~T} \\
(\mathrm{~A})\end{array}$ & \\
\hline \multirow[t]{2}{*}{ I. III } & 1489 & 5 & 5 & 5 & 5 & 5 & 5 & 5 & 5 & 5 & 5 & 5 & 5 & 5 \\
\hline & 29 & 0 & 0 & 0 & 0 & 0 & 3 & 0 & 0 & 0 & 0 & 0 & 0 & 1 \\
\hline \multirow{4}{*}{ I } & 52 & 2 & 3 & 0 & 0 & 2 & 0 & 0 & 0 & 0 & 0 & 1 & 0 & I \\
\hline & $52 \mathrm{~A} / 79$ & 2 & 0 & 0 & 0 & 0 & 0 & 0 & 0 & 0 & 0 & 0 & 0 & I \\
\hline & 80 & 4 & 0 & 0 & 2 & 0 & 0 & 0 & 0 & 0 & 0 & 0 & 0 & 1 \\
\hline & $3 \mathrm{~A}$ & 0 & 0 & 1 & 0 & I & 0 & 1 & 1 & 0 & 0 & 0 & 3 & 0 \\
\hline \multirow{8}{*}{ II } & $3 C$ & 0 & 0 & 1 & 1 & 1 & 0 & 0 & 1 & 0 & 1 & 0 & I & 0 \\
\hline & 55 & 0 & 0 & 0 & 0 & 1 & 0 & 0 & I & 0 & 0 & 0 & 2 & 0 \\
\hline & 71 & 0 & 0 & 0 & 0 & 0 & 0 & 0 & 1 & 0 & 0 & 0 & 2 & 0 \\
\hline & 6 & 4 & 4 & 5 & 4 & 5 & 3 & 5 & I & 5 & 5 & 5 & 4 & 5 \\
\hline & $42 \mathrm{E}$ & 0 & 0 & 3 & 0 & 3 & 0 & 3 & 0 & I & 0 & 0 & 3 & 2 \\
\hline & 47 & 4 & 0 & 5 & 0 & 4 & 0 & 4 & 0 & 5 & I & 0 & 5 & 5 \\
\hline & 53 & 0 & 0 & I & 0 & 4 & 0 & I & 0 & 0 & 5 & 0 & 4 & 3 \\
\hline & 54 & 1 & I & 5 & 0 & 5 & 5 & 2 & 1 & 0 & 5 & 5 & 5 & 5 \\
\hline \multirow[t]{5}{*}{ III } & 75 & 1 & 4 & I & 0 & 0 & 5 & $\vec{I}$ & 0 & 0 & 5 & 5 & 5 & I \\
\hline & 77 & I & I & 4 & 0 & 0 & 0 & 4 & 0 & 0 & I & I & 4 & 4 \\
\hline & $83 \mathrm{~A}$ & 4 & 4 & 5 & 2 & 4 & 3 & 4 & I & 0 & I & 5 & 5 & 5 \\
\hline & 84 & I & 0 & 4 & 0 & I & I & I & 0 & 0 & 4 & 5 & 5 & 4 \\
\hline & 85 & 0 & 0 & 0 & 4 & 3 & 3 & I & 5 & 5 & 5 & 3 & 0 & 0 \\
\hline \multirow{5}{*}{$\begin{array}{l}\text { Miscell- } \\
\text { aneous } \\
\text { Experi- } \\
\text { mental }\end{array}$} & 81 & 4 & 0 & 0 & 0 & 0 & 0 & 0 & 0 & 0 & 0 & 0 & 0 & 0 \\
\hline & 95 & 0 & 0 & 0 & 0 & 0 & 0 & 0 & 0 & 0 & 1 & 0 & 3 & 0 \\
\hline & 90 & 0 & 0 & 0 & 0 & 0 & 0 & 0 & 0 & 5 & I & 3 & I & I \\
\hline & 88 & 0 & I & 4 & 0 & I & 5 & I & 0 & 5 & 5 & 5 & 4 & 5 \\
\hline & 2009 & 4 & 0 & 0 & 0 & I & 0 & 0 & I & 0 & 0 & 0 & I & 0 \\
\hline \multirow[t]{2}{*}{ Test } & 8719 & 0 & 0 & 1 & 0 & 1 & 0 & 0 & 0 & 0 & 0 & 0 & 2 & 0 \\
\hline & $42 \mathrm{C}$ & 0 & 0 & 0 & I & I & 0 & 0 & I & 0 & 4 & 0 & 4 & 0 \\
\hline
\end{tabular}

$5=$ Titre on strain $1489: 4=10^{-1}-10^{-2}, 3=10^{-3}-10^{-4}, 2=10^{-5}-10^{-6}$ of titre on strain $1489 ; 1=$ very weak lysis: $I=$ inhibition reaction; $0=$ no lysis.

${ }^{*}$ Serological group of phage. 


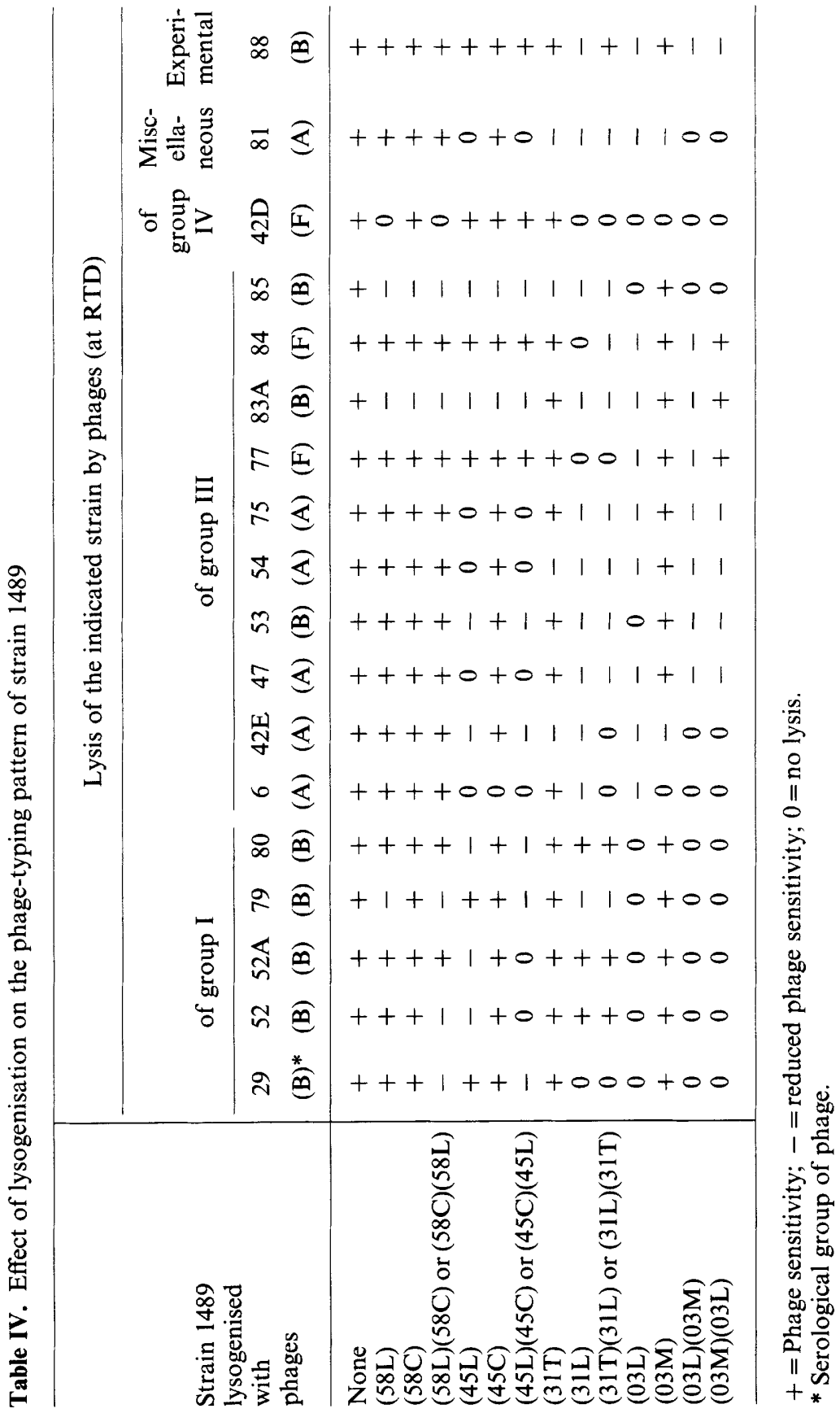


Table V. Comparison of the phage-typing patterns of the double lysogens of strain 1489 with those of the original host strains of the lysogenising phages

\begin{tabular}{|c|c|c|c|}
\hline \multirow{2}{*}{$\begin{array}{l}\text { Host } \\
\text { strain no. }\end{array}$} & \multicolumn{2}{|c|}{ Phage-typing pattern at RTD of the } & \multirow{2}{*}{$\begin{array}{c}\text { Lysogenising } \\
\text { phages }\end{array}$} \\
\hline & host strain & strain 1489 after lysogenisation & \\
\hline 5058 & $6 / 47 / 53 / 54 / 77 / 83 \mathrm{~A} / 84 / 85 / 88$ & $52 \mathrm{~A} / 80 / 6 / 42 \mathrm{E} / 47 / 53 / 54 / 75 / 77 / 84 / 81 / 88$ & $(58 \mathrm{~L})(58 \mathrm{C})$ \\
\hline 5045 & $77 / 84 / 85 / 88$ & $77 / 84 / 42 \mathrm{D} / 88$ & $(45 \mathrm{~L})(45 \mathrm{C})$ \\
\hline 5531 & 88 & $52 / 52 \mathrm{~A} / 80 / 88$ & $(31 \mathrm{~T})(31 \mathrm{~L})$ \\
\hline 6803 & Untypable & Untypable & $(03 \mathrm{~L})(03 \mathrm{M})$ \\
\hline 6803 & Untypable & $77 / 83 \mathrm{~A} / 84$ & $(03 \mathrm{M})(03 \mathrm{~L})$ \\
\hline
\end{tabular}

$45 \mathrm{~L}, 31 \mathrm{~L}$ and $03 \mathrm{~L}$, resulted in a greater narrowing of the pattern of susceptibility to phage lysis. In general, lysogenic immunity was not serogroup specific, and the typing patterns of the single lysogens did not correspond to those of the MRSA strains from which the phages had been derived.

The phage-typing patterns of the double lysogens showed a somewhat greater resemblance to those of the strains that had yielded the two phages (table IV). Thus, nos. 1489(58L)(58C) and 1489(58C)(58L) had identical phage-typing patterns that were narrower than the patterns of either no. $1489(58 \mathrm{~L})$ or no. $1489(58 \mathrm{C})$, but they differed from that of strain 5058 by six reactions. Both double lysogens with phages $45 \mathrm{~L}$ and $45 \mathrm{C}$ differed from strain 5045 by two reactions, and those with phages $31 \mathrm{~L}$ and $31 \mathrm{~T}$ differed from strain 5531 by three reactions. The double lysogens with the two 03 phages differed in phage-typing pattern according to the order of addition of the phages; no. $1489(03 \mathrm{M})(30 \mathrm{~L})$ had the typing pattern $77 / 83 \mathrm{~A} / 84$, but no. $1489(03 \mathrm{~L})(03 \mathrm{M})$, like strain 6803 , was untypable.

\section{Lysogenicity of strains isolated in 1973-75}

Only nine MRSA strains were isolated in 1973 (table I). Six of them had the broad group-III pattern $(47 / 53 / 54 / 77 / 83 \mathrm{~A} / 84 / 85 / 88)$ and three the pattern $77 / 84 / 85 / 88$. The lysogenic state of one representative strain of each phage-typing pattern was identical to that of strain 5058 and strain 5045 respectively.

One of the four strains isolated in 1974 (no. 1536) was lysed only by phage 88 and was found to carry a single prophage; this, when characterised serologically and by host range, was identical with phage C, the phage common to MRSA strains with various phage-typing patterns isolated in 1980 and subsequently (Beard-Pegler and Vickery, 1985).

Six strains were isolated in 1975; two had pro- phages identical with those of strain 5058 and one with those of strain 5045. The other three strains were from patients who were already infected when admitted to the hospital and who had acquired the organisms overseas. Their lysogenic phages were unrelated to any we had encountered, and strains of this description have not been seen since.

\section{Lysogenicity of strains isolated in 1976-80}

Strains with the typing pattern $84 / 85$ at 100 RTD were predominant during this period (table I). Fifteen of them were examined; phages were obtained from only seven, even after repeated treatment with ultraviolet light or mitomycin C, and the yield was very low in comparison with that from all the rest of the MRSA strains tested. All of the phages had the serological and host-range characters of phage $C$.

Representative strains with the other 100 RTD patterns encountered during this period $(83 \mathrm{~A} / 85 /$ $95 / 90 / 88,77 / 83 \mathrm{~A} / 84 / 85 / 95 / 90 / 88$, and $\mathrm{NT}^{*}$ ) were identical lysogenically with similar strains isolated after 1980 (Beard-Pegler and Vickery, 1985) in that they carried a phage with the characters of $C$.

\section{Lysogenicity of strains isolated in 1985}

MRSA strains with the typing pattern 29/85/88 at 100 RTD were first seen in 1984; they increased in frequency from $2 \%$ in this year to $10 \%$ in the first 4 months of 1985 (table I). Two phages were isolated from representative strains: phage $C$ and another designated $13 \mathrm{M}$ (table III). Phage $13 \mathrm{M}$ had a wide host range and belonged to serological group $\mathrm{B}$, but lysogenisation of strain 1489 did not bring about any change in phage-typing pattern.

\section{Discussion}

MRSA strains isolated in our hospital during the last 20 years can be differentiated by their phage- 
typing patterns and their state of lysogeny. Four phage-typing patterns predominated in 1965-75 and five quite different ones in 1976-85. Gillespie et al. (1984) reported a variety of phage-typing patterns among MRSA isolated in a Melbourne hospital between 1969 and 1981 .

Each of the four predominant strains seen in the RPAH in the earlier time-period harboured two prophages, and the eight phages could be differentiated by serological group and lytic spectrum. The presence of two distinct prophages in each host strain argues against Lacey's (1972) view that all MRSA form part of "the same" staphylococcal strain. Our eight phages differed from lysogenic phages reported in MRSA in other countries (Schaefler et al., 1981).

Lysogenisation of a non-lysogenic MRSA strain with each of the eight phages led to various degrees of narrowing of its phage-typing pattern. As observed by Asheshov and Rippon (1959) and Rountree (1959), prophage immunity did not run parallel with the serological group of the respective phages. Lysogenisation with pairs of phages that had occurred together naturally in MRSA resulted in even greater narrowing of the typing pattern. The double lysogens had patterns that generally resembled and were occasionally indistinguishable from that of the strain of origin of the phage pair.

MRSA from our hospital after 1980 differed from the earlier isolates in that, as shown by Beard-Pegler and Vickery (1985), all of them harboured the lysogenic phage $\mathrm{C}$, whatever their phage-typing pattern. The introduction of this phage into the non-lysogenic MRSA strain had little effect on its phage-typing pattern; this also contrasts sharply with the effect of lysogenisation with the phages from our earlier MRSA isolates.

The few isolations of MRSA made in the years 1973-75 included representatives of the four phagetyping patterns that had been prevalent in earlier years, but one strain isolated in 1974 (no. 1536; lysed by phage 88 at RTD) was of particular interest because it was the first to yield phage $\mathrm{C}$.

\section{REFERENCES}

Asheshov E H, Jevons M P 1963 The effect of heat on the ability of a host strain to support the growth of a staphylococcus phage. Journal of General Microbiology 31:97-107.

Asheshov E H, Rippon J E 1959 Changes in typing pattern of phage-type 80 staphylococci. Journal of General Microbiology 20:634-643.

Beard-Pegler MA, Vickery AM 1985 Lysogenicity of methicillinresistant strains of Staphylococcus aureus. Journal of Medical Microbiology 20:147-155.
In 1976, the frequency of isolation of MRSA began to increase again. At this time, strains that were untypable at RTD but lysed by phages 84 and 85 at 100 RTD appeared, and they became the predominant MRSA strains for the next 3 years. Such strains had been seen elsewhere in Australia at a somewhat earlier date (Vickery, unpublished; Gillespie et al., 1984). The fact that a number of those isolated at the RPAH yielded phage C suggests a relation to strain 1536 . Strains with this phage-typing pattern isolated after 1980 (described as $84 / 85 / 90$ by Beard-Pegler and Vickery, 1985) all yielded phage $\mathrm{C}$, and some of them other phages as well. The reason for the poor inducibility of the earlier isolates with this phage-typing pattern is not known, nor is the relative immunity of these and other MRSA strains isolated after 1980 to the typing phages. These appear not to be attributable to the presence of restriction enzymes, because heating does not increase phage sensitivity or prophage inducibility (Asheshov and Jevons, 1963).

Our findings give strong indications that MRSA strains isolated after 1976 are quite distinct from those of earlier years. Plasmid-DNA analysis of isolates from Australian hospitals also provides evidence that the recent isolates are a distinct group and can be differentiated from earlier isolates (Townsend et al., 1983; Gillespie et al., 1984). Recent reports suggest that strains similar to current Australian strains have been responsible for infections in London hospitals (Bradley et al., 1985; Brumfitt et al., 1985). The continued spread of MRSA strains is thus a matter of great interest, and further investigation of their lysogenicity may contribute to an understanding of their epidemiology.

We thank Dr Phyllis Rountree and Professor Yvonne Cossart for their invaluable advice, continuing interest and encouragement, Theresa Rice for technical assistance, and Toni Cozens for her assistance in the preparation of this manuscript.

Blair J E, Williams R E O 1961 Phage typing of staphylococci. Bulletin of the World Health Organization 24:771784.

Bradley J M, Noone P, Townsend D E, Grubb W B 1985 Methicillin-resistant Staphylococcus aureus in a London hospital. Lancet 1:1493-1495.

Brumfitt W, Dixson S, Hamilton-Miller J M T 1985 Resistance to antiseptics in methicillin and gentamicin resistant Staphylococcus aureus. Lancet 1:1442-1443.

Cafferkey M T, Hone R, Falkiner F R, Keane C T, Pomeroy H 1983 Gentamicin and methicillin-resistant Staphylococcus 
aureus in Dublin hospitals: clinical and laboratory studies. Journal of Medical Microbiology 16:117-127.

Gillespie M T, May J W, Skurray R A 1984 Antibiotic susceptibilities and plasmid profiles of nosocomial methicillin-resistant Staphylococcus aureus: a retrospective study. Journal of Medical Microbiology 17:295-310.

Gorrill R H, Gray R A 1956 The induction of bacteriophage in staphylococci. Journal of General Microbiology 14:167173.

King K, Brady L M, Thomson M, Harkness J L 1982 Antibioticresistant staphylococci in a teaching hospital. Medical Journal of Australia 2:461:465.

Lacey R W 1972 Genetic control in methicillin-resistant strains of Staphylococcus aureus. Journal of Medical Microbiology 5:497-508.

McDonald M, Hurse A, Sim K N 1981 Methicillin-resistant Staphylococcus aureus bacteraemia. Medical Journal of Australia 2:191-194.

Pavillard R et al. 1982 Epidemic of hospital-acquired infection due to methicillin-resistant Staphylococcus aureus in major Victorian hospitals. Medical Journal of Australia 1:451454.
Rippon J E 1956 The classification of bacteriophages lysing staphylococci. Journal of Hygiene 54:213-226.

Rountree P M 1959 Changes in the phage-typing patterns of staphylococci following lysogenization. Journal of General Microbiology 20:620-633.

Rountree P M, Beard M A 1968 Hospital strains of Staphlococcus aureus, with particular reference to methicillin-resistant strains. Medical Journal of Australia 2:1163-1168.

Rountree P M, Vickery A M 1973 Further observations on methicillin-resistant staphylococci. Medical Journal of Australia 1:1030-1034.

Schaefler S et al. 1981 Emergence of gentamicin-resistant and methicillin-resistant Staphylococcus aureus strains in New York City hospitals. Journal of Clinical Microbiology 13:754-759.

Townsend D E, Grubb W B, Ashdown N 1983 Genetics of drug resistance in methicillin-resistant Staphylococcus aureus from Australian hospitals. Journal of Hospital Infection 4:331-337.

Vickery A M, Beard-Pegler M A, Rountree P M 1983 Strain differentiation in methicillin-resistant Staphylococcus aureus. Pathology 15:235-240. 